\title{
Expression levels of VEGF-C and VEGFR-3 in renal cell carcinoma and their association with lymph node metastasis
}

\author{
XIUMING LI ${ }^{1}$, DIANBIN SONG ${ }^{1}$, HUI LIU ${ }^{2}$, ZHIYONG WANG ${ }^{1}$, \\ GUANG MA ${ }^{1}$, MAN YU ${ }^{1}$, YONG ZHANG ${ }^{3}$ and YU ZENG ${ }^{4}$ \\ ${ }^{1}$ Department of Urology, The Affiliated Hospital of Chengde Medical University, Chengde, Hebei 067000; \\ ${ }^{2}$ Key Laboratory of Ethnomedicine of Ministry of Education, Center on Translational Neuroscience, \\ School of Pharmacy, Minzu University of China, Beijing 100081; Departments of ${ }^{3}$ Pathology and \\ ${ }^{4}$ Urology, Liaoning Cancer Hospital and Institute, Shenyang, Liaoning 110042, P.R. China
}

Received May 24, 2020; Accepted February 24, 2021

DOI: 10.3892/etm.2021.9986

\begin{abstract}
Renal cell carcinoma (RCC) is the most common form of kidney cancer. Vascular endothelial growth factor-C (VEGF-C) and its receptor, VEGFR-3, are involved in lymphangiogenesis. The aim of the present study was to investigate the expression levels of VEGF-C and VEGFR-3 in RCC, and their association with lymphatic vessel density (LVD) and lymph node metastasis. The mRNA expression levels of VEGF-C in $40 \mathrm{RCC}$ tissues and 10 normal renal tissues were determined by reverse transcription-semiquantitative PCR. The differential expression of VEGF-C and VEGFR-3 was examined by immunohistochemistry. Using an anti-D2-40 antibody as a lymphatic marker, the morphology and structure of lymphatic vessels in tissues was examined, and the LVD was calculated. VEGF-C mRNA expression in RCC tissues was higher than that in normal renal tissues, and VEGF-C mRNA expression in the lymph node metastasis group was higher than that in the non-lymph node metastasis group. The positive expression rate of VEGF-C and VEGFR-3 in RCC tissues was significantly higher than that in normal renal tissues. VEGF-C expression in the lymph node metastasis group was significantly higher than that in the non-lymph node metastasis group, and the positive expression of VEGF-C was associated with the clinical staging of RCC. In addition, there was a correlation between VEGF-C and VEGFR-3 expression in tumor cells. The LVD around the tumor was higher than that in the center of the tumor tissues and normal renal tissues, and it was closely associated with lymphatic invasion and lymph node metastasis. Overall, the current findings demonstrated that the VEGF-C/VEGFR-3
\end{abstract}

Correspondence to: Professor Yu Zeng, Department of Urology, Liaoning Cancer Hospital and Institute, 44 Xiaoheyan Road, Shenyang, Liaoning 110042, P.R. China

E-mail: zengyud07@foxmail.com

Key words: renal cell carcinoma, lymphatic vessel density, lymph node metastasis, vascular endothelial growth factor-C, vascular endothelial growth factor receptor 3 signaling pathway promoted lymphangiogenesis around the tumor and provided an approach for tumor lymphatic invasion and lymph node metastasis. Therefore, VEGFC and VEGFR-3 expression may serve an important role in the initiation and development of RCC.

\section{Introduction}

Kidney cancer is among the 10 most common cancers, and it is estimated that 73,750 individuals were diagnosed with kidney cancer in 2020 in the United States (1). Renal cell carcinoma (RCC), also known as renal cancer, is the most common form of kidney cancer and is responsible for up to $85 \%$ of kidney cancer cases in the United States; it is more frequent in males than in females (ratio, 1.7:1) (2), and the majority of patients are of older age, with an average age of 64 years (3). The disease encompasses $>10$ histological and molecular subtypes, of which clear cell RCC (ccRCC) is the most common and accounts for the majority of kidney cancer-associated deaths (4). Localized RCC can be successfully managed with surgery, whereas metastatic RCC is refractory to conventional chemotherapy $(5,6)$. The tumor size, Fuhrman nuclear grade, tumor histology, performance status and surrounding fat invasion are well-known prognostic factors (7); however, lymph node metastasis also serves a key role in the survival of patients with locally advanced RCC, and patients with lymph node metastases often have a poor prognosis (8). As RCC advances, the 5-year survival rate from 93\% decreases to $67 \%$ for patients with regional metastases and $12 \%$ for those with distant metastatic disease (9).

The generation of new lymphatic vessels through lymphangiogenesis and the remodeling of existing lymphatics are considered to be important steps in cancer metastasis (10). Tumor cells can either acquire access to the lymphatic system by inducing intra-tumoral lymphangiogenesis or by invading pre-existing lymphatics in the surrounding tissue (11). Recent evidence indicates that peri-tumoral or intra-tumoral lymphangiogenesis is a precursor for lymphatic metastasis in the majority of carcinoma and melanoma cases (12). The ability of a tumor to induce and activate lymphatic growth has been positively associated with metastasis (13). 
Lymphangiogenesis is a complex process regulated by a number of factors (14). It has been reported that vascular endothelial growth factor-C (VEGF-C) and its receptor, VEGFR-3, are the basis of lymphatic vessel formation (15). VEGF-C/VEGFR-3 signaling is important for the progression of various types of cancer, such as head and neck cancer, melanoma and breast cancer (16-18). These receptors are expressed mainly on endothelial cells, but are also expressed on tumor cells (19). During tumor development, lymphatic endothelial cells substantially expand in response to VEGFR-3 engagement by VEGF-C produced in the tumor microenvironment, a process known as tumor-associated lymphangiogenesis (20). Therefore, VEGF-C can induce tumor lymphangiogenesis and promote lymph node metastasis (21). During the process of tumor lymphangiogenesis and lymphatic metastasis, the molecules associated with the VEGF-C/VEGFR-3 signaling pathway, such as Furin-like protease 1, contactin-1, prospero homeobox protein 1, lymphatic vessel endothelial hyaluronic acid receptor 1, podoplanin, SOX-18 and C-X-C chemokine receptor type 4 , serve a crucial role in the complex biological activities of tumor growth and progression (22). In a variety of experimental tumors, such as non-small cell lung cancer, colorectal cancer and bladder cancer, VEGFR-3 inhibitory antibodies or VEGF-C-targeted small interfering RNA molecules can decrease the incidence of lymph node metastasis $(19,23,24)$. However, to the best of our knowledge, there are no studies concerning the specific profile of lymphangiogenesis in RCC.

The aim of the present study was to investigate the association between VEGF-C/VEGFR-3 and lymphangiogenesis, clinical pathology and lymph node metastasis in RCC.

\section{Materials and methods}

Patients and samples. A total of 40 surgically resected samples of RCC with single tumors were collected from the Affiliated Hospital of Chengde Medical University (Chengde, China) between July 2016 and September 2017. Among these, 18 cases were treated with nephron-sparing surgery and 22 cases underwent radical nephrectomy, with 11 of the aforementioned 22 patients exhibiting lymph node metastasis and undergoing regional lymph node dissection. There were 25 males and 15 females aged between 24 to 65 years with an average age of 51.9 years. Pathological analysis confirmed the diagnosis of RCC in all cases, including 37 cases of ccRCC, 2 cases of papillary RCC and 1 case of chromophobe RCC. Patients did not receive radiotherapy, chemotherapy or immunotherapy prior to surgery. A total of 10 adjacent normal renal tissues (meeting the requirement of $>2 \mathrm{~cm}$ above the edge of the tumor) were selected as the controls. The RCC tissues were excised rapidly for histological investigation and RNA isolation. According to the WHO criteria published in 2004 (25), 20 cases were highly differentiated, 11 cases were moderately differentiated and 9 cases were poorly differentiated or undifferentiated. According to the clinical staging of the American Joint Committee on Cancer for renal cell carcinoma in 2002 (26), there were 22 cases of stage I, 6 cases of stage II, 11 cases of stage III and 1 case of stage IV. Among all cases, there were 29 cases without lymph node metastasis and 11 cases with renal hilar lymph node metastasis.
$R N A$ extraction and reverse transcription-semiquantitative $P C R$ (RT-sqPCR). Total RNA was isolated from freshly dissected tissues using TRIzol ${ }^{\circledR}$ reagent (Invitrogen; Thermo Fisher Scientific, Inc.) according to the manufacturer's protocol. Total RNA was used as template to synthesize the first chain of cDNA using PrimeScript ${ }^{\mathrm{TM}}$ 1st Strand cDNA Synthesis Kit (Takara Bio, Inc.) according to the manufacturer's protocol. $\beta$-actin served as the internal control. Primers were synthesized by Sangon Biotech Co., Ltd., and were as follows: VEGF-C (target fragment, $373 \mathrm{bp}$ ) forward, 5'-AGA GACGGCACAAGGATGAG-3' and reverse, 5'-ATCGGC AGGAAGTGTGATTG-3'; ACTB (target fragment, 453 bp) forward, 5'-AGCGGGAAATCGTGCGTGAC-3' and reverse, 5'-ACATCTGCTGGAAGGTGGAC-3'. The thermocycling conditions were as follows: $3 \mathrm{~min}$ of pre-denaturation at $95^{\circ} \mathrm{C}$, followed by 30 cycles of denaturation at $95^{\circ} \mathrm{C}$ for $15 \mathrm{sec}$ and annealing at $60^{\circ} \mathrm{C}$ for $30 \mathrm{sec}$. Finally, the mixture was incubated at $72^{\circ} \mathrm{C}$ for $5 \mathrm{~min}$ and cooled to $4^{\circ} \mathrm{C}$. PCR-amplified products were analyzed by electrophoresis on a $2 \%$ agarose gel using ethidium bromide staining, and photographs were captured with a UV transmission analyzer (Gene Company, Ltd.). The density scanning of the electrophoresis strips of the amplified products was performed using Quantity One software v4.6.6 (Bio-Rad Laboratories, Inc.), and the results were expressed as the absorbance (A) ratio of VEGF-C to $\beta$-actin $\left(\mathrm{A}_{\mathrm{VEGF-C}} / \mathrm{A}_{\beta \text {-actin }}\right)$.

Immunohistochemistry $(I H C)$. Tissue samples were fixed with $10 \%$ formalin at $4^{\circ} \mathrm{C}$ for $12 \mathrm{~h}$ and embedded in paraffin. The paraffin-embedded samples were cut into $4-\mu$ m-thick sections, which were then blocked with $3 \%$ hydrogen peroxide for $60 \mathrm{~min}$ at room temperature. The sections were dewaxed in toluene and rehydrated through sequential changes of alcohol (100, 95 and $70 \%)$ and distilled water. For antigen retrieval, the tissue sections were incubated with $0.01 \mathrm{M}$ sodium citrate $(\mathrm{pH} 6)$ in a microwave oven at $95^{\circ} \mathrm{C}$ for $10 \mathrm{~min}$, followed by blocking with $5 \%$ normal goat serum (cat. no. ZLI-9021; OriGene Technologies, Inc.) for $10 \mathrm{~min}$ at room temperature, the tissue sections were incubated with rabbit anti-human VEGF-C monoclonal antibody (cat. no. BA0548; 1:200; Wuhan Boster Biological Technology Co., Ltd.), rabbit anti-human VEGFR-3 monoclonal antibody (cat. no. A01276-3; 1:200; Wuhan Boster Biological Technology Co., Ltd.) and mouse anti-human D2-40 monoclonal antibody (cat. no. ZM-0465; undiluted; OriGene Technologies, Inc.) for $12 \mathrm{~h}$ at $4^{\circ} \mathrm{C}$. Following primary antibody incubation, the tissue sections were incubated with HRP-labeled secondary antibodies [anti-rabbit (cat. no. BM3894, 1:1,000) and anti-mouse (cat. no. BM3895; 1:1,000; both from Wuhan Boster Biological Technology Co., Ltd.)] for $1 \mathrm{~h}$ at room temperature. DAB (cat. no. AR1000; Wuhan Boster Biological Technology Co., Ltd.) was used for coloration, and hematoxylin was used for counterstaining at $37^{\circ} \mathrm{C}$ for $2 \mathrm{~min}$. PBS buffer solution was used as a negative control to substitute the primary antibody.

Histopathological evaluation. The results of VEGF-C and VEGFR-3 IHC staining were determined. The cytoplasm and/or membrane of RCC cells that were clear brown yellow particles was set as the standard, and the results were analyzed 
A

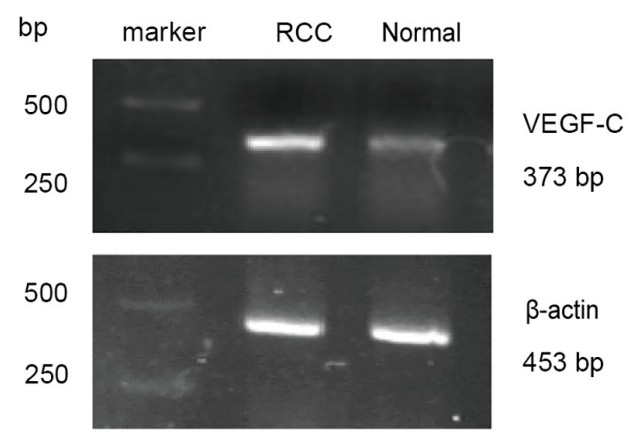

B

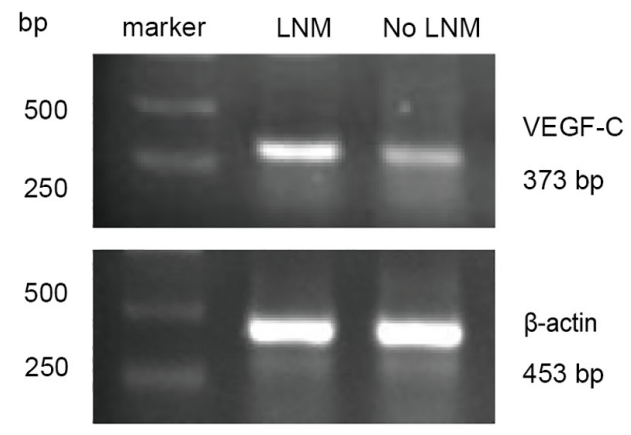

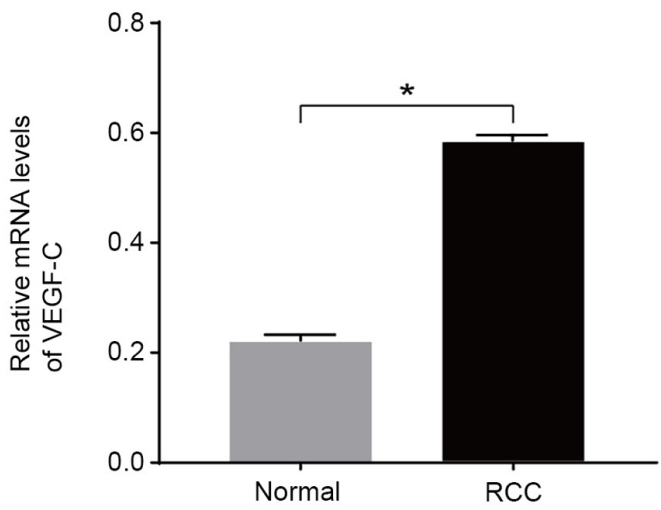

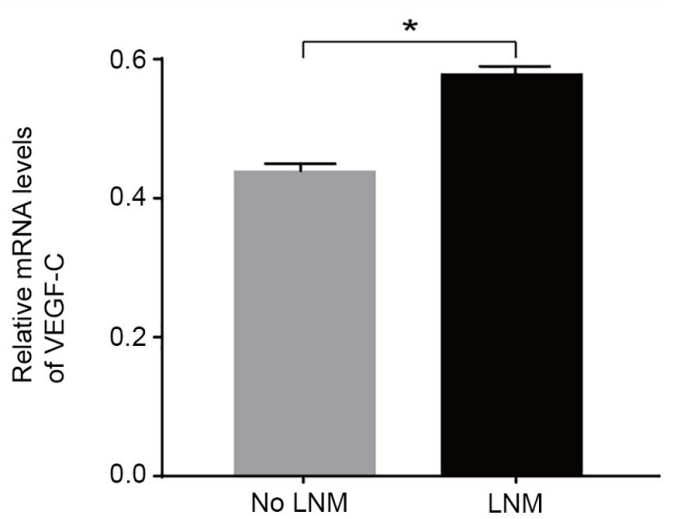

Figure 1. Relative mRNA levels of VEGF-C. VEGF-C mRNA expression was analyzed by reverse transcription-semiquantitative PCR in (A) normal renal tissues $(n=10)$ and RCC $(n=40)$ tissues, and $(B)$ LNM $(n=11)$ and no LNM $(n=29)$ groups. $\beta$-actin was used as an internal control. Data are presented as the mean \pm SD. Significance was determined using the Mann-Whitney U test. ${ }^{*} \mathrm{P}<0.05$. RCC, renal cell carcinoma; LNM, lymph node metastasis; VEGF-C, vascular endothelial growth factor-C.

using the double scoring method as previously described by Volm et al (27). In the homogeneously dyed tumor area, 5 high magnification views (x200) of the light microscope were selected according to the percentage of positive cells (A value) and the staining intensity (B value). The percentage of positive cells was scored as follows: 0 , No obvious positive cells; 1 , $<25 \%$ positive cells; $2,25-50 \%$ positive cells; and $3,>50 \%$ positive cells. The staining intensity was scored as follows: 0 , No coloring; 1, light brown-yellow; 2, brown-yellow; and 3, brown. The final score was determined by adding the score for the percentage of positive staining cells (A value) with that of the staining intensity (B value). The final value thus ranged from 0 to 6 , and was as follows: 0 , negative (-); $1-2$, weak (+); 3-4, moderate (++); and 5-6, strong expression (+++). The immunohistochemical staining was grouped into two categories: Low expression (-/+) and high expression (++/+++).

The IHC streptavidin-peroxidase conjugated method (SP Ready-To-Use kit; cat. no. SP-9000; OriGene Technologies, Inc.) was used to detect D2-40 expression. The positively stained D2-40 protein was mainly located in the cytoplasm and/or cell membrane of the lymphatic endothelium, and was presented as a brown-yellow color. The determination of lymphatic vessel density (LVD) was according to the method previously described by Weidner et al (28), which was used to observe and select 5 regions with maximum LVD (hot spots) under a light microscope (magnification, x100), and then 5 optic fields were counted under x200 magnification (covering an area of $0.74 \mathrm{~mm}^{2}$ ) and the average LVD value was used. All these assessments were made by two independent observers. LVD was defined as the number of vessels $/ \mathrm{mm}^{2}$. Intra-tumoral LVD was defined as D2-40 ${ }^{+}$vessels that were in close contact with tumor cells. Peritumoral LVD was defined as D2- $40^{+}$vessels in the fibrous capsule or at the interface of tumor and adjacent kidney.

Statistical analysis. Statistical analyses were performed using GraphPad Prism v8.0.1 (GraphPad Software, Inc.). Continuous variables were presented as the mean $\pm \mathrm{SD}$ of three independent experiments, and the difference between two groups was analyzed using unpaired Student's t-test. One-way ANOVA with Bonferroni post-hoc test was used to compare differences among multiple groups. The categorical data was analyzed using $\chi^{2}$ test. Mann-Whitney U test was used to evaluate significant differences for the RT-sqPCR data. Spearman's correlation analysis was used for correlation analysis. $\mathrm{P}<0.05$ was considered to indicate a statistically significant difference.

\section{Results}

VEGF-C mRNA expression. The results of the RT-sqPCR analysis revealed a small amount of VEGF-C mRNA in the 10 normal renal tissues, with a relative expression level of $0.250 \pm 0.104$; however, in the 40 RCC tissues, the relative VEGF-C expression was $0.576 \pm 0.191$, which was significantly higher than that in normal tissues (Fig. 1A). The relative mRNA expression levels of VEGF-C were significantly higher 
Table I. Differences in VEGF-C mRNA expression among different clinicopathological parameters in patients with RCC ( $\mathrm{n}=40$ ).

\begin{tabular}{|c|c|c|c|}
\hline Characteristics & $\mathrm{N}$ & Relative mRNA expression & P-value ${ }^{a}$ \\
\hline Kidney tissues & & & $0.001^{\mathrm{b}}$ \\
\hline $\mathrm{RCC}$ & 40 & $0.576 \pm 0.191$ & \\
\hline Normal & 10 & $0.250 \pm 0.104$ & \\
\hline Sex & & & 0.372 \\
\hline Male & 25 & $0.596 \pm 0.215$ & \\
\hline Female & 15 & $0.544 \pm 0.146$ & \\
\hline Age, years & & & 0.388 \\
\hline$<55$ & 18 & $0.606 \pm 0.229$ & \\
\hline$\geq 55$ & 22 & $0.552 \pm 0.156$ & \\
\hline Differentiation & & & 0.932 \\
\hline Good or moderate & 31 & $0.575 \pm 0.210$ & \\
\hline Poor & 9 & $0.581 \pm 0.113$ & \\
\hline Lymphatic metastasis & & & $0.018^{\mathrm{b}}$ \\
\hline Negative & 29 & $0.532 \pm 0.181$ & \\
\hline Positive & 11 & $0.693 \pm 0.174$ & \\
\hline Clinical stages & & & $0.002^{\mathrm{b}}$ \\
\hline $\mathrm{I}+\mathrm{II}$ & 28 & $0.517 \pm 0.177$ & \\
\hline III+IV & 12 & $0.714 \pm 0.153$ & \\
\hline
\end{tabular}

Data are presented as the mean $\pm \mathrm{SD}$. ${ }^{\mathrm{a} M a n n}$-Whitney $\mathrm{U}$ test. ${ }^{\mathrm{b}} \mathrm{P}<0.05$. RCC, renal cell carcinoma.

in the lymph node metastasis group compared with in the non-lymph node metastasis group, with relative expression levels of $0.693 \pm 0.174$ and $0.532 \pm 0.181$, respectively (Fig. 1B). There were no significant differences in VEGF-C mRNA expression according to age, sex and differentiation, but VEGF-C mRNA expression was significantly higher in the group with lymphatic metastasis compared with in the group without lymphatic metastasis, as well as in patients with higher stages compared with in patients with lower stages (Table I). These data indicated that VEGF-C may serve an important role in RCC progression.

VEGF-C expression in normal renal and $R C C$ tissues. VEGF-C expression in renal tissues was further observed via IHC. According to the percentage of positively stained cells and staining intensity as described in the materials and methods section, a total of $40 \mathrm{RCC}$ samples were divided into the low VEGF-C expression $(n=20)$ and high VEGF-C expression $(n=20)$ groups. Specific and representative IHC-staining intensity patterns for the VEGF-C protein in the RCC samples are presented in Fig. 2A-D. Only 3/10 normal renal tissue samples exhibited weak VEGF-C expression (Fig. 2E). The positive expression rate (including weak, moderate and strong staining intensity) of VEGF-C in the RCC group was significantly higher than that in the normal renal tissue group (85 vs. $30 \%$, respectively; Fig. 2F). VEGF-C expression was independent of age, sex and differentiation, but was significantly associated with lymph node metastasis and clinical staging of RCC (Table II). These results indicated that VEGF-C expression was upregulated in RCC tissues and associated with tumor progression.
VEGFR-3 expression. Considering that VEGFR-3, as a receptor of VEGF-C, is widely expressed on lymphatic endothelial cells (29), the association between VEGF-C and VEGFR-3 expression in RCC tissues was further investigated. As shown in Fig. 3A and B, compared with in normal renal tissues, VEGFR-3 expression was markedly higher in the tumor tissues. Additionally, VEGFR-3 ${ }^{+}$lymphatic vessels were detected in RCC tissues (Fig. 3C). Furthermore, Spearman's correlation analysis demonstrated a positive correlation between VEGF-C and VEGFR-3 expression in RCC tissues (Fig. 3D). These results support the notion that VEGF-C/VEGFR-3 serve a crucial role in RCC progression.

LVD in RCC and surrounding tissues, and its association with lymph node metastasis. Given that lymphangiogenesis serves an important role in the process of lymph node metastasis (30), the lymphatic marker D2-40 was used to stain the lymphatic tubes, and LVD was analyzed. IHC staining revealed that the staining for $\mathrm{D} 2-40^{+}$cells was mainly located in the cell membrane of lymphatic endothelial cells, and was presented as a brown-yellow color (Fig. 4A). It was observed that the lumen of the lymphatic vessels in the tumor appeared narrow (Fig. 4B) and the lymphatic vessels around the tumor were functionally dilated with an enlarged diameter (Fig. 4C). The peritumoral LVD was 14.16 \pm 2.58 , which was significantly higher than that in the RCC $(9.74 \pm 2.48)$ and

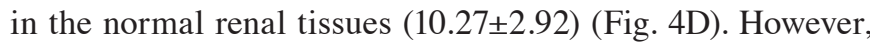
the LVD between the tumor and normal renal tissues did not exhibit a significant difference (Fig. 4D). The LVD of the peritumoral tissues in 11 cases in the lymph node metastasis group was $15.24 \pm 1.86$, which was significantly 
A

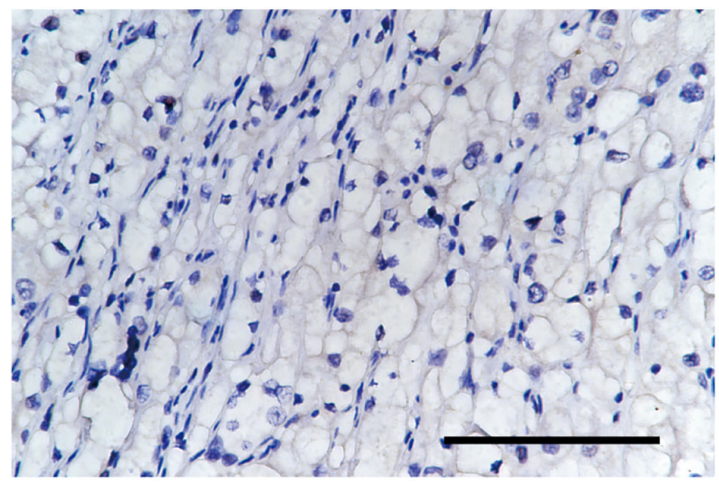

C

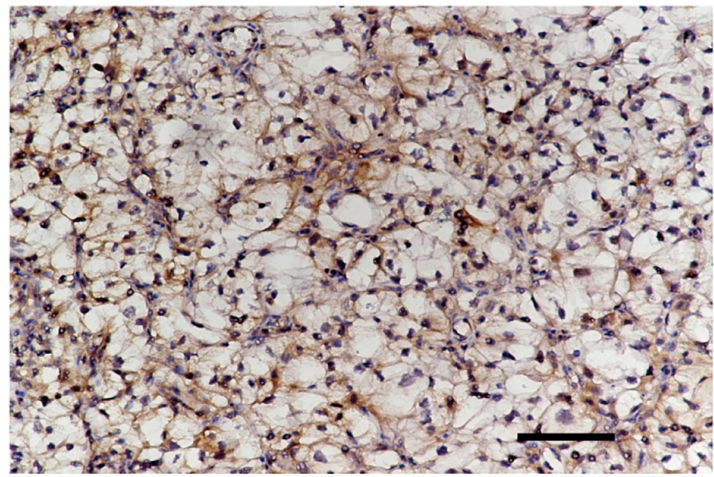

E

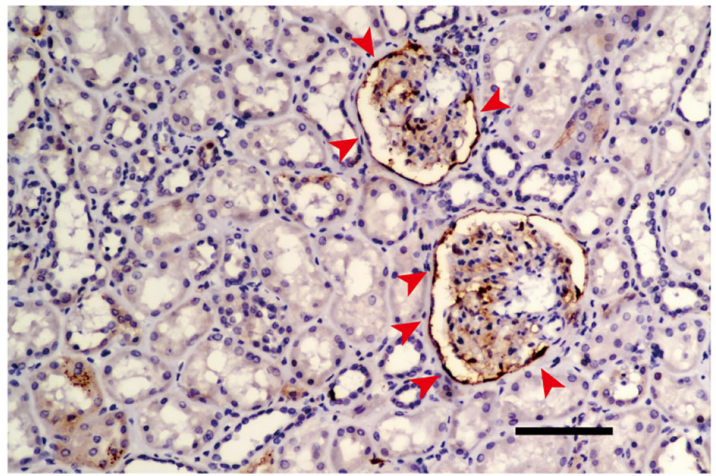

$\mathrm{B}$

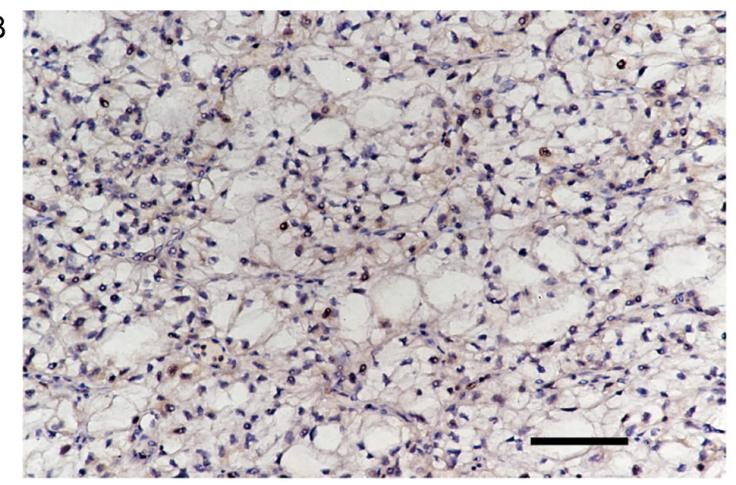

$\mathrm{D}$

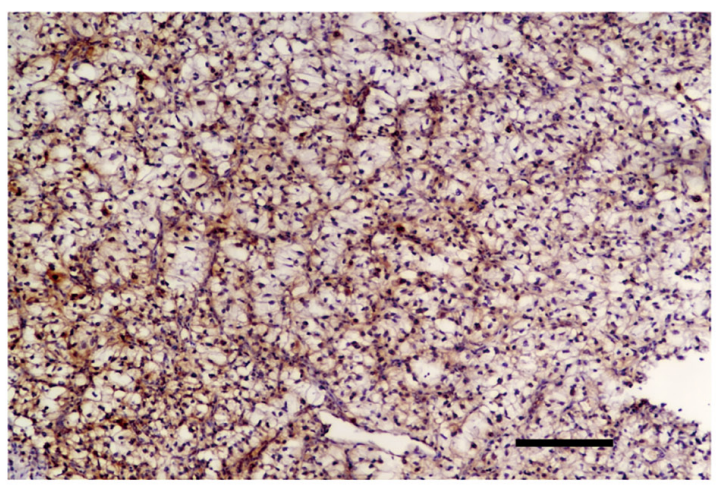

$\mathrm{F}$

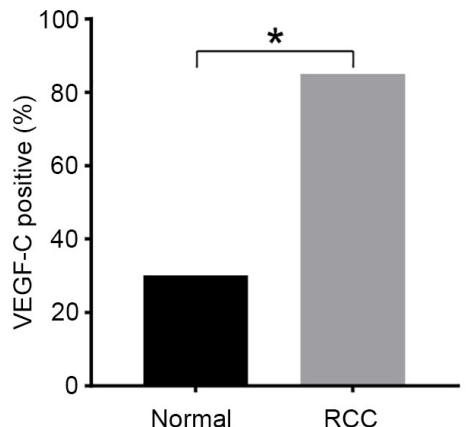

Figure 2. Immunohistochemical staining of VEGF-C expression in RCC and normal renal tissues. (A) Negative VEGF-C expression in RCC. (B) Weak positive expression of VEGF-C in RCC. (C) Moderate positive expression of VEGF-C in RCC. (D) Strong positive expression of VEGF-C in RCC. (E) VEGF-C expression in glomerular epithelial cells (arrowheads). Scale bars, $100 \mu \mathrm{m}$. (F) Statistical analysis of the VEGF-C positive expression rate. Statistical significance was determined using the $\chi^{2}$ test. ${ }^{*} \mathrm{P}<0.05$. RCC, renal cell carcinoma; VEGF-C, vascular endothelial growth factor-C.

higher than that in the 29 cases without lymph node metastasis $(13.37 \pm 2.03)$ (Fig. 4E). These data indicated that the lymphatic vessels around the tumor may be important in promoting lymph node metastasis in RCC.

\section{Discussion}

VEGF-C is a newly discovered lymphatic growth factor that belongs to the VEGF family. It was first cloned from the cDNA library of the PC-3 human prostate cancer cell line in 1996, and is mainly expressed in lymph nodes, the heart and placenta (31). A previous study demonstrated that VEGF-C has two existing forms, Mr31000 and Mr21000 (32). The latter is a mature form of VEGF-C that is produced during the process of protein hydrolysis, and acts as a ligand to bind to VEGFR-3, thereby inducing the proliferation and migration of lymphatic endothelial cells by activating VEGFR-3 and promoting lymphatic duct hyperplasia (33). VEGFR-3, also known as Flt4, is a member of the tyrosine kinase receptor family and it consists of extracellular (including 7 immunoglobulin homologous domains), transmembrane and intracellular domains (31). VEGFR-3 is widely expressed in vascular endothelial cells of early embryos, as well as being expressed on lymphatic endothelial cells in the late embryonic development stage and in healthy adults $(34,35)$. In the present study, positive VEGFR-3 expression in the lymphatic endothelium of RCC was observed. However, it has been revealed that a small amount of VEGFR-3 is expressed in microcapillaries and renal tubular endothelial cells; thus, VEGFR-3 may be associated with chronic kidney disease and tissue inflammation (36), and its role warrants further investigation. D2-40 is a highly specific marker of the lymphatic endothelium that is not expressed by the blood vessel endothelium (37). Thus, the morphological structure of the lymphatic capillary wall can be visually displayed and distinguished from capillary vessels using D2-40. 
Table II. Association between VEGF-C expression and clinicopathological parameters of patients with renal cell carcinoma $(\mathrm{n}=40)$.

\begin{tabular}{|c|c|c|c|c|}
\hline \multirow[b]{2}{*}{ Characteristics } & \multirow[b]{2}{*}{$\mathrm{N}$} & \multicolumn{2}{|c|}{ VEGF-C expression } & \multirow[b]{2}{*}{ P-value } \\
\hline & & Low & High & \\
\hline Sex & & & & 0.327 \\
\hline Male & 25 & 11 & 14 & \\
\hline Female & 15 & 9 & 6 & \\
\hline Age, years & & & & 0.525 \\
\hline$<55$ & 18 & 8 & 10 & \\
\hline$\geq 55$ & 22 & 12 & 10 & \\
\hline Differentiation & & & & 0.449 \\
\hline Good or moderate & 31 & 17 & 14 & \\
\hline Poor & 9 & 3 & 6 & \\
\hline Lymphatic metastasis & & & & $0.013^{\mathrm{b}}$ \\
\hline Negative & 29 & 18 & 11 & \\
\hline Positive & 11 & 2 & 9 & \\
\hline Clinical stages & & & & $0.038^{\mathrm{b}}$ \\
\hline $\mathrm{I}+\mathrm{II}$ & 28 & 17 & 11 & \\
\hline III+IV & 12 & 3 & 9 & \\
\hline
\end{tabular}

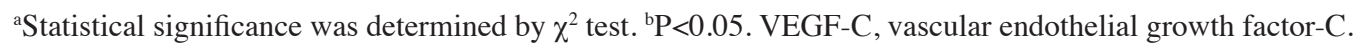

A

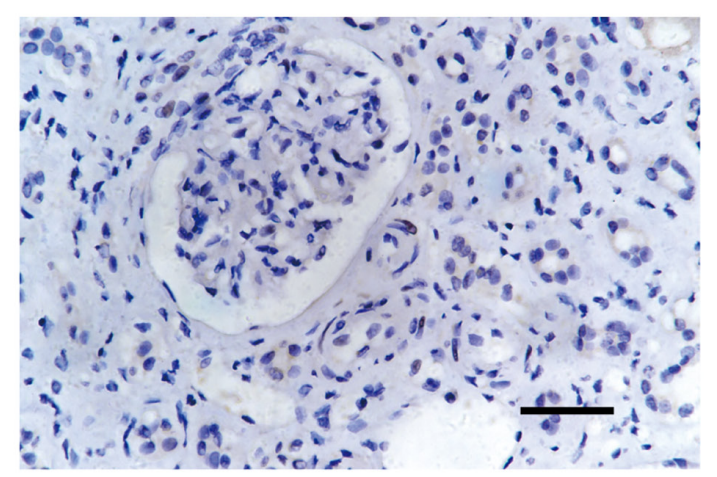

C

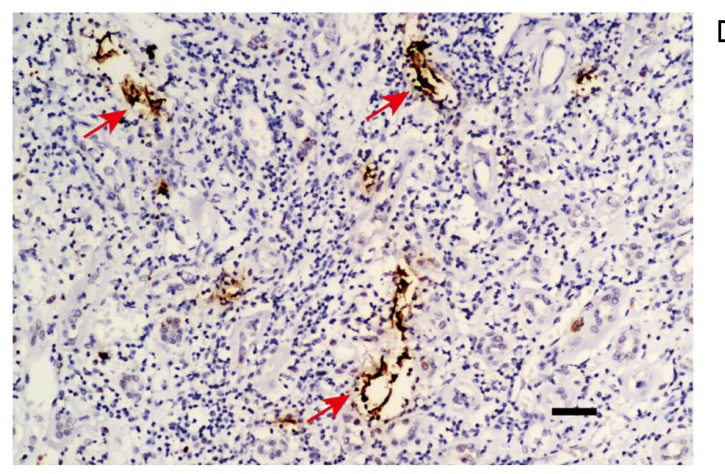

$\mathrm{B}$

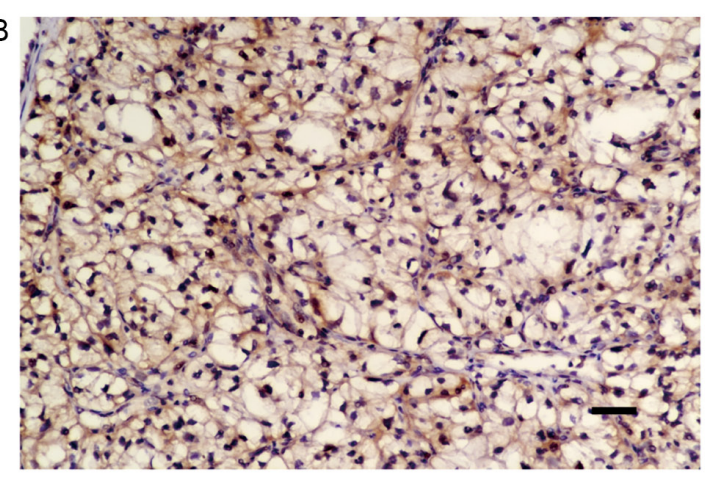

D

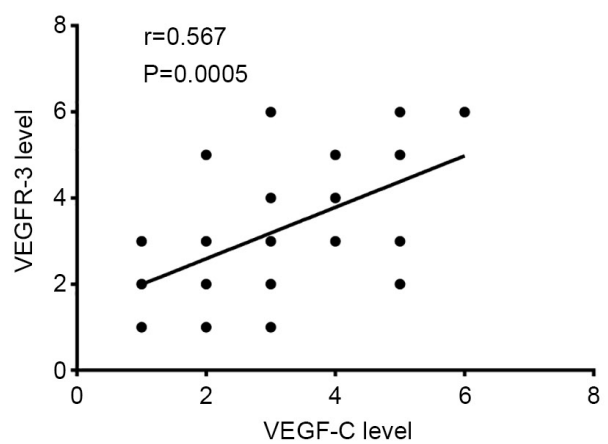

Figure 3. Immunohistochemical staining of VEGFR-3 expression. VEGFR-3 immunohistochemical staining in (A) normal renal tissues and (B) RCC tissues. (C) Lymphatic endothelial cells in RCC tissues were VEGFR-3 ${ }^{+}$(indicated by arrows). Scale bars, $100 \mu \mathrm{m}$. (D) Correlation between VEGF-C and VEGFR-3 expression in RCC tissues. Statistical significance was determined by Spearman's correlation test. RCC, renal cell carcinoma; VEGF-C, vascular endothelial growth factor-C; VEGFR-3, VEGF receptor-3.

Lymphatic metastasis is achieved through the invasion of cells of mature lymphatic vessels, and subsequent metastasis to the lymph nodes (38). Therefore, the more tumor cells become dissociated from the primary tumor, the greater the possibility of metastasis. Reports on the presence of lymphatic vessels in tumors remain inconsistent. Some studies have 
A

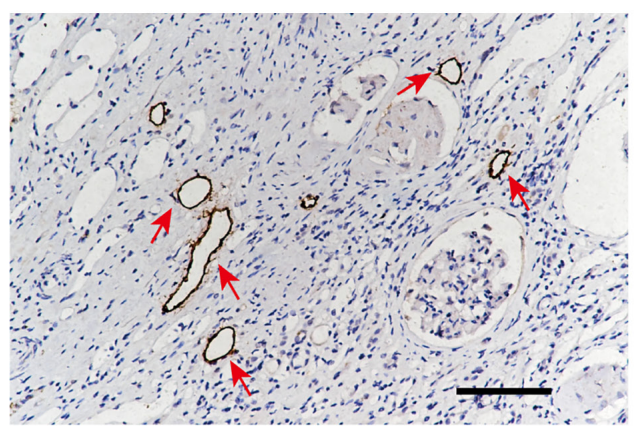

B
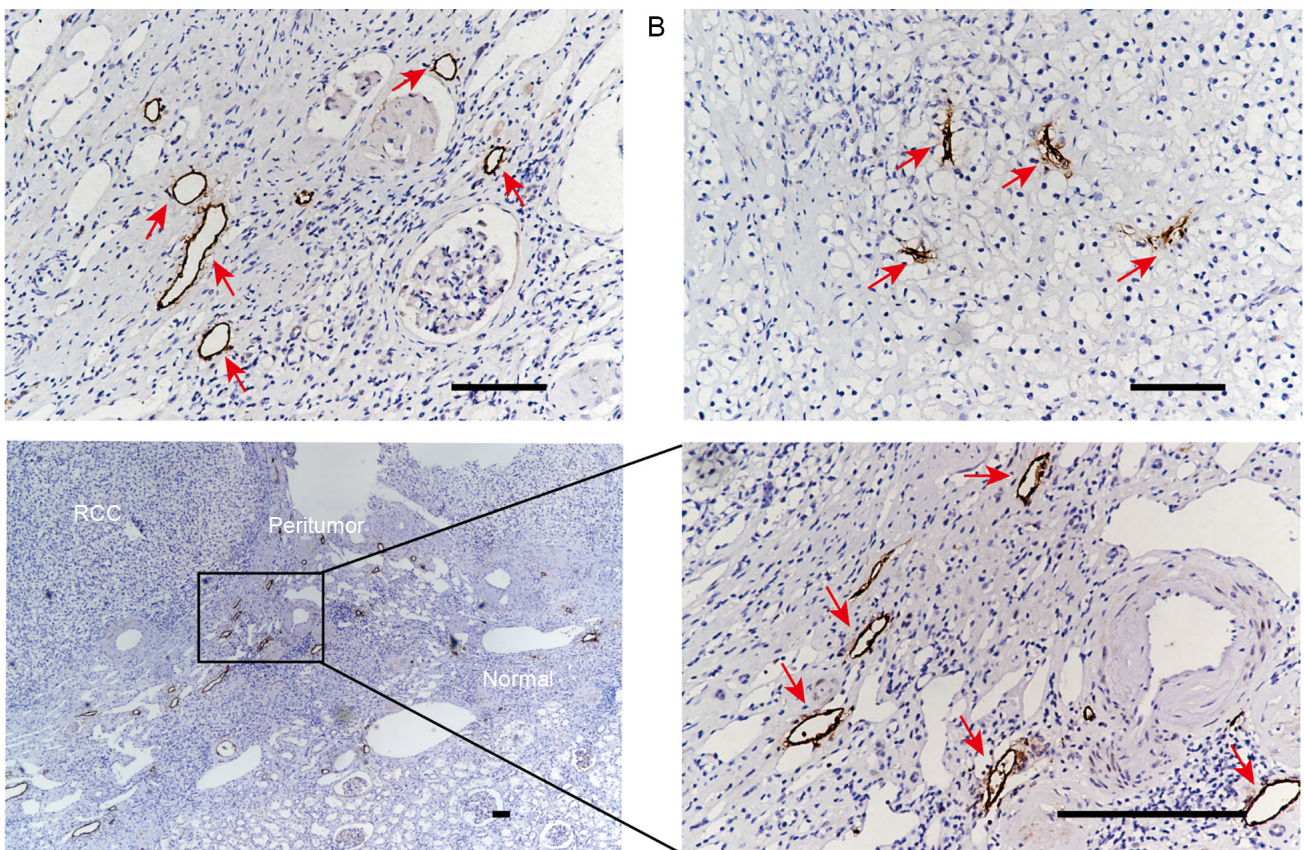

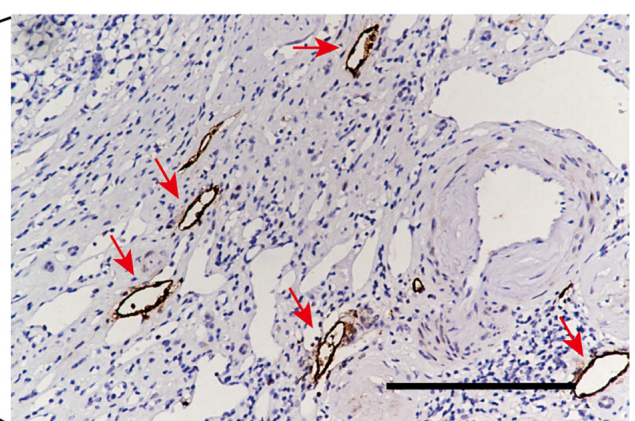

E

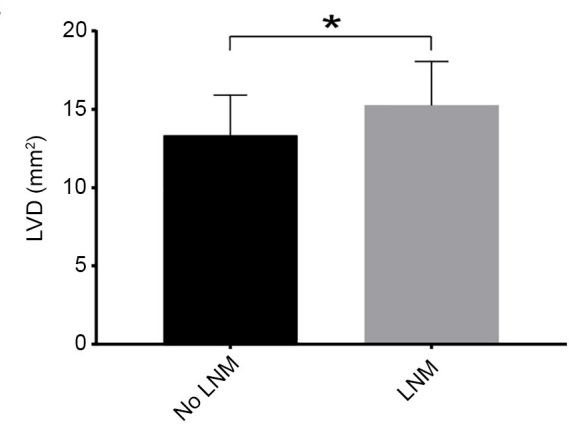

Figure 4. LVD in RCC and normal renal tissues. Lymphatic tubes were stained with D2-40. (A) Representative morphological structure of lymphatic vessels (indicated by arrows) in normal renal tissues. (B) Lymphatic capillaries were often irregularly shaped and collapsed in RCC tissues (indicated by arrows). (C) LVD around the tumor was higher than that in the tumor tissues; lymphatic vessels around the tumor were functionally dilated with an enlarged diameter (indicated by arrows). Scale bars, $100 \mu \mathrm{m}$. (D) Quantification of LVD in normal renal, RCC and peritumoral tissues. One-way ANOVA with Bonferroni post-hoc test was used for statistical analysis. (E) Statistical analysis of LVD in the LNM and no LNM groups. Significance was determined using an unpaired t-test. Data are presented as the mean $\pm \mathrm{SD}$. * $\mathrm{P}<0.05$. RCC, renal cell carcinoma; LVD, lymphatic vessel density; LNM, lymph node metastasis.

indicated the presence of lymphatic vessels in tumors, while others have demonstrated contrasting results $(10,39)$. Although it remains controversial whether tumors can induce the genesis of lymphatic vessels, it has been demonstrated that the excessive expression of lymphogenerative factors, such as VEGF-C, can induce more lymphatic vessels and facilitate metastasis through tumor lymphatic vessels (14). In experiments using mouse tumor models, it has been demonstrated that VEGF-C induces lymphangiogenesis and that tumor cells enter the capillary lymphatic vessels (40). Ruddell et al (41) has revealed that VEGF-C induces the expansion of collecting lymphatic vessels to facilitate lymph flow, which in turn transports a large number of tumor cells to the lymph nodes and contributes to the distant metastasis of tumors.

At present, VEGF-C expression in the majority of human malignant tumors, such as esophageal (42), colorectal (24) and gastric cancer (43), is known to be markedly higher than that in normal tissues. However, to the best of our knowledge, there are no studies available on VEGF-C expression and its association with lymphatic metastasis in RCC. The present study used RT-sqPCR to detect VEGF-C mRNA expression in RCC tissues, which was significantly higher than that in normal renal tissues. VEGF-C mRNA expression in the lymph node metastasis group was also higher than that in the non-lymph node metastasis group. In addition, VEGF-C mRNA expression in patients with stage III and IV RCC was higher than that in patients with stage I and II RCC (the majority of cases with stage III and IV RCC were accompanied by lymph node metastasis). Moreover, the present study demonstrated a correlation between VEGF-C and VEGFR-3 expression in tumor tissues. The current results suggested that the VEGF-C/VEGFR-3 axis may serve an important role in the progression of RCC.

It has been demonstrated that VEGFR- $3^{+}$and dilated functional lymphatic vessels are located around tumors in mouse models of sarcoma, but functional lymphatic vessels are absent within solid tumors (44). Furthermore, despite the presence of VEGF-C and other lymphangiogenesis-associated factors, the formation of functional lymphatic vessels in a murine sarcoma model was prevented (40). The present study used D2-40 as 
a marker to observe the morphology and structure of microlymphatic vessels, revealing that there were microlymphatic vessels in RCC tissues; however, there were no statistically significant differences in LVD between RCC and normal renal tissues. Additionally, the present results demonstrated that the lymphatic vessels in the tumor were small and irregular, and most were collapsed, which may not be functional. This may be due to the rapid proliferation of cancer cells in tumor tissues and increased interstitial hydrostatic pressure, resulting in the occlusion of the lumen of neoplastic lymphatic vessels (45). The current results were consistent with those of the aforementioned studies $(40,44)$. However, the present study indicated that there were functionally dilated lymphatic vessels in the tissues surrounding the tumor. The LVD in peritumoral tissues in the lymph node metastasis group was higher than that in the non-lymph node metastasis group. Voss et al (46) observed a significant inflammatory response around ccRCC tissues, while macrophages secreted VEGF-C, which may lead to the proliferation of peritumoral lymphatic vessels.

Although the lymphatic vessels within the tumor tissues may be dysfunctional, the increased and dilated lymphatic vessels around the tumor increase the probability of lymphatic metastasis of tumor cells. According to the current study, there may be three reasons for this: i) The neoplastic lymphatic vessels around the tumor may assist the transportation of oxygen and nutrients in the blood flow, thus promoting the proliferation of tumor cells and increasing the probability of the metastasis of tumor cells through lymphatic vessels (47); ii) the abnormal proliferation and expansion of lymphatic vessels around the tumor may make it easier for tumor cells to metastasize through lymphatic vessels (48); iii) the overexpression of VEGF-C in cancer cells may act as a chemokine, guiding cancer cells to migrate to VEGFR-3-expressing lymphatic endothelial cells (21). These reasons suggest that, to a certain extent, although there were no functionally enlarged lymphatic vessels in RCC tissues, there may be a close association with lymph node metastasis.

In conclusion, high VEGF-C expression in RCC may serve a role in targeting its specific receptor, VEGFR-3, which thus may promote the formation of peritumoral lymphatic vessels. The increase in LVD and the expansion of the lumen diameter in the surrounding tissues of the tumors may be crucial for lymphatic infiltration and lymph node metastasis. Therefore, targeted therapy for lymphangiogenesis in RCC may be a novel treatment strategy.

\section{Acknowledgements}

Not applicable.

\section{Funding}

The present study was supported by The Science and Technology Research and Development Project of Chengde, Hebei province (grant no. 201801A101).

\section{Availability of data and materials}

All data generated or analyzed during this study are included in this published article.

\section{Authors' contributions}

XL and YZe designed the study and confirmed the authenticity of all the raw data. DS, HL and GM performed the experiments. ZW, MY and YZh analyzed the data. All authors read and approved the final version of the manuscript.

\section{Ethics approval and consent to participate}

The present study was approved by the Ethics Committee of the Affiliated Hospital of Chengde Medical University (Chengde, China). All participants provided written informed consent.

\section{Patient consent for publication}

Not applicable.

\section{Competing interests}

The authors declare that they have no competing interests.

\section{References}

1. Siegel RL, Miller KD and Jemal A: Cancer statistics, 2020. CA Cancer J Clin 70: 7-30, 2020.

2. Siegel RL, Miller KD and Jemal A: Cancer statistics, 2017. CA Cancer J Clin 67: 7-30, 2017.

3. Barata PC and Rini BI: Treatment of renal cell carcinoma: Current status and future directions. CA Cancer J Clin 67: 507-524, 2017.

4. Linehan WM, Srinivasan R and Schmidt LS: The genetic basis of kidney cancer: A metabolic disease. Nat Rev Urol 7: 277-285, 2010.

5. Hsieh JJ, Purdue MP, Signoretti S, Swanton C, Albiges L, Schmidinger M, Heng DY, Larkin J and Ficarra V: Renal cell carcinoma. Nat Rev Dis Primers 3: 17009, 2017.

6. Choueiri TK and Motzer RJ: Systemic therapy for metastatic renal-cell carcinoma. N Engl J Med 376: 354-366, 2017.

7. Yu KJ, Keskin SK, Meissner MA, Petros FG, Wang X, Borregales LD, Gu C, Tamboli P, Matin SF, Wood CG and Karam JA: Renal cell carcinoma and pathologic nodal disease: Implications for American joint committee on cancer staging. Cancer 124: 4023-4031, 2018.

8. Bazzi WM, Sjoberg DD, Feuerstein MA, Maschino A, Verma S, Bernstein M, O'Brien MF, Jang T, Lowrance W, Motzer RJ and Russo P: Long-term survival rates after resection for locally advanced kidney cancer: Memorial Sloan kettering cancer center 1989 to 2012 experience. J Urol 193: 1911-1916, 2015.

9. Tannir NM, Pal SK and Atkins MB: Second-line treatment landscape for renal cell carcinoma: A comprehensive review. Oncologist 23: 540-555, 2018.

10. Stacker SA, Williams SP, Karnezis T, Shayan R, Fox SB and Achen MG: Lymphangiogenesis and lymphatic vessel remodelling in cancer. Nat Rev Cancer 14: 159-172, 2014.

11. Padera TP, Kadambi A, di Tomaso E, Carreira CM, Brown EB, Boucher Y, Choi NC, Mathisen D, Wain J, Mark EJ, et al: Lymphatic metastasis in the absence of functional intratumor lymphatics. Science 296: 1883-1886, 2002.

12. Lala PK, Nandi P and Majumder M: Roles of prostaglandins in tumor-associated lymphangiogenesis with special reference to breast cancer. Cancer Metastasis Rev 37: 369-384, 2018.

13. Karaman S and Detmar M: Mechanisms of lymphatic metastasis. J Clin Invest 124: 922-928, 2014.

14. Yu P, Wu G, Lee HW and Simons M: Endothelial metabolic control of lymphangiogenesis. Bioessays 40: e1700245, 2018.

15. Alitalo K, Tammela T and Petrova TV: Lymphangiogenesis in development and human disease. Nature 438: 946-953, 2005.

16. Beasley NJ, Prevo R, Banerji S, Leek RD, Moore J, van Trappen P, Cox G, Harris AL and Jackson DG: Intratumoral lymphangiogenesis and lymph node metastasis in head and neck cancer. Cancer Res 62: 1315-1320, 2002. 
17. Dadras SS, Paul T, Bertoncini J, Brown LF, Muzikansky A, Jackson DG, Ellwanger U, Garbe C, Mihm MC and Detmar M: Tumor lymphangiogenesis: A novel prognostic indicator for cutaneous melanoma metastasis and survival. Am J Pathol 162: 1951-1960, 2003

18. Nathanson SD: Insights into the mechanisms of lymph node metastasis. Cancer 98: 413-423, 2003.

19. Chen JC, Chang YW, Hong CC, Yu YH and Su JL: The role of the VEGF-C/VEGFRs axis in tumor progression and therapy. Int J Mol Sci 14: 88-107, 2012.

20. Garnier L, Gkountidi AO and Hugues S: Tumor-associated lymphatic vessel features and immunomodulatory functions. Front Immunol 10: 720, 2019.

21. Su JL, Yen CJ, Chen PS, Chuang SE, Hong CC, Kuo IH, Chen HY, Hung MC and Kuo ML: The role of the VEGF-C/VEGFR-3 axis in cancer progression. Br J Cancer 96: 541-545, 2007.

22. Wang J, Huang Y, Zhang J, Wei Y, Mahoud S, Bakheet AM, Wang L, Zhou S and Tang J: Pathway-related molecules of VEGFC/D-VEGFR3/NRP2 axis in tumor lymphangiogenesis and lymphatic metastasis. Clin Chim Acta 461: 165-171, 2016.

23. Takahashi S: Vascular endothelial growth factor (VEGF), VEGF receptors and their inhibitors for antiangiogenic tumor therapy. Biol Pharm Bull 34: 1785-1788, 2011.

24. Tacconi C, Correale C, Gandelli A, Spinelli A, Dejana E, D'Alessio S and Danese S: Vascular endothelial growth factor C disrupts the endothelial lymphatic barrier to promote colorectal cancer invasion. Gastroenterology 148: 1438-1451.e8, 2015.

25. Moch H, Cubilla AL, Humphrey PA, Reuter VE and Ulbright TM: The 2016 WHO classification of tumours of the urinary system and male genital organs-part A: Renal, penile, and testicular tumours. Eur Urol 70: 93-105, 2016.

26. Howard GE and Wood CG: Staging refinements in renal cell carcinoma. Curr Opin Urol 16: 317-320, 2006.

27. Volm M, Koomagi R and Mattern J: Prognostic value of vascular endothelial growth factor and its receptor Flt-1 in squamous cell lung cancer. Int J Cancer 74: 64-68, 1997.

28. Weidner N, Semple JP, Welch WR and Folkman J: Tumor angiogenesis and metastasis-correlation in invasive breast carcinoma. N Engl J Med 324: 1-8, 1991.

29. Schwager S and Detmar M: Inflammation and lymphatic function. Front Immunol 10: 308, 2019.

30. Yamakawa M, Doh SJ, Santosa SM, Montana M, Qin EC, Kong H, Han KY, Yu C, Rosenblatt MI, Kazlauskas A, et al: Potential lymphangiogenesis therapies: Learning from current antiangiogenesis therapies-a review. Med Res Rev 38: 1769-1798, 2018.

31. Joukov V, Pajusola K, Kaipainen A, Chilov D, Lahtinen I, Kukk E, Saksela O, Kalkkinen N and Alitalo K: A novel vascular endothelial growth factor, VEGF-C, is a ligand for the Flt4 (VEGFR-3) and KDR (VEGFR-2) receptor tyrosine kinases. EMBO J 15: 290-298, 1996.

32. Kukk E, Lymboussaki A, Taira S, Kaipainen A, Jeltsch M, Joukov V and Alitalo K: VEGF-C receptor binding and pattern of expression with VEGFR-3 suggests a role in lymphatic vascular development. Development 122: 3829-3837, 1996.

33. Katsuta M, Miyashita M, Makino H, Nomura T, Shinji S, Yamashita K, Tajiri T, Kudo M, Ishiwata $T$ and Naito $Z$ : Correlation of hypoxia inducible factor-1alpha with lymphatic metastasis via vascular endothelial growth factor- $\mathrm{C}$ in human esophageal cancer. Exp Mol Pathol 78: 123-130, 2005.

34. Oliver G: Lymphatic vasculature development. Nat Rev Immunol 4: 35-45, 2004.
35. Jacquemier J, Mathoulin-Portier MP, Valtola R, Charafe-Jauffret E, Geneix J, Houvenaeghel G, Puig B, Bardou VJ, Hassoun J, Viens P and Birnbaum D: Prognosis of breast-carcinoma lymphagenesis evaluated by immunohistochemical investigation of vascular-endothelial-growth-factor receptor 3. Int J Cancer 89: 69-73, 2000.

36. Kinashi H, Ito Y, Sun T, Katsuno T and Takei Y: Roles of the TGF- $\beta$-VEGF-C pathway in fibrosis-related lymphangiogenesis. Int J Cancer 19: 2487, 2018

37. Kaiserling E: Immunohistochemical identification of lymph vessels with D2-40 in diagnostic pathology. Pathologe 25: 362-374, 2004 (In German)

38. Zavyalova MV, Denisov EV, Tashireva LA, Savelieva OE, Kaigorodova EV, Krakhmal NV and Perelmuter VM: Intravasation as a key step in cancer metastasis. Biochemistry (Mosc) 84: 762-772, 2019

39. Tammela T,He Y, Lyytikka J, Jeltsch M, Markkanen J, Pajusola K, Ylä-Herttuala S and Alitalo K: Distinct architecture of lymphatic vessels induced by chimeric vascular endothelial growth factor-C/vascular endothelial growth factor heparin-binding domain fusion proteins. Circ Res 100: 1468-1475, 2007.

40. Leu AJ, Berk DA, Lymboussaki A, Alitalo K and Jain RK: Absence of functional lymphatics within a murine sarcoma: A molecular and functional evaluation. Cancer Res 60: 4324-4327, 2000.

41. Ruddell A, Harrell MI, Minoshima S, Maravilla KR, Iritani BM, White SW and Partridge SC: Dynamic contrast-enhanced magnetic resonance imaging of tumor-induced lymph flow. Neoplasia 10: 706-713, 2008

42. Li J, Xie Y, Wang X, Jiang C, Yuan X, Zhang A, Liu C, Pang L, $\mathrm{Li} \mathrm{F}$ and $\mathrm{Hu} \mathrm{J}$ : Overexpression of VEGF-C and MMP-9 predicts poor prognosis in Kazakh patients with esophageal squamous cell carcinoma. PeerJ 7: e8182, 2019.

43. Chen H, Guan R, Lei Y, Chen J, Ge Q, Zhang X, Dou R, Chen H, Liu H, Qi X, et al: Lymphangiogenesis in gastric cancer regulated through Akt/mTOR-VEGF-C/VEGF-D axis. BMC Cancer 15: 103, 2015.

44. Tammela T, Zarkada G, Wallgard E, Murtomäki A, Suchting S, Wirzenius M, Waltari M, Hellström M, Schomber T, Peltonen R, et al: Blocking VEGFR-3 suppresses angiogenic sprouting and vascular network formation. Nature 454: 656-660, 2008.

45. Ma Q, Dieterich LC and Detmar M: Multiple roles of lymphatic vessels in tumor progression. Curr Opin Immunol 53: 7-12, 2018.

46. Voss M, Steidler A, Grobholz R, Weiss C, Alken P, Michel MS and Trojan L: The lymphatic system and its specific growth factor vascular endothelial growth factor $\mathrm{C}$ in kidney tissue and in renal cell carcinoma. BJU Int 104: 94-99, 2009.

47. Yue H, Wang J, Chen R, Hou X, Li J and Lu X: Gene signature characteristic of elevated stromal infiltration and activation is associated with increased risk of hematogenous and lymphatic metastasis in serous ovarian cancer. BMC Cancer 19: 1266, 2019.

48. Ma Q, Dieterich LC, Ikenberg K, Bachmann SB, Mangana J, Proulx ST, Amann VC, Levesque MP, Dummer R, Baluk P, et al: Unexpected contribution of lymphatic vessels to promotion of distant metastatic tumor spread. Sci Adv 4: eaat4758, 2018.

This work is licensed under a Creative Commons Attribution-NonCommercial-NoDerivatives 4.0 International (CC BY-NC-ND 4.0) License. 